\title{
Preliminary Development of MyAras: Level 1 Mobile Virtual Lab
}

\author{
$\underline{\text { https://doi.org/10.3991/ijet.v14i24.12125 }}$
}

\author{
N.Abd. Rahman ${ }^{(凶)}$, J. Mohd Ali, M.A. Baharom \\ Universiti Kebangsaan Malaysia, Bangi Selangor, Malaysia \\ norlizajkkp@ukm.ukm.edu.my
}

\begin{abstract}
Process control is an essential aspect in chemical engineering, which has been emphasized in Dynamic and Control Process course (KKKR 3684) theoretically and through a conventional laboratory experimental, A2 (Tuning and Control) for hands-on learning. The tank level is chosen as the controlled variable to introduce control scheme to students. This conventional lab uses an old version facility and requires constant maintenance resulting lab schedule being postponed several times. Besides that, every experiment must be carried out in a group of four to five students thus the access and learning time per student is limited. As an alternative to this conventional laboratory, a mobile-based virtual lab has been designed to cater the limitations using a mobile application. The proposed virtual lab is known as MyAras and is developed using Android Studio software of version 2.3.3, which also a strategy to facing the 4.0 Industrial revolution. MyAras is a mobile virtual application and time independent, cost-effective, easy access and provides unlimited self-learning period for all students. Level 1 means the mobile virtual lab is still in the development stage and has not been fully launched to students. A questionnaire has been given to students and lecturers regarding their awareness and the importance of mobile virtual lab prior to its development. Preliminary study has found that $81 \%$ of students have shown their interest in running the virtual lab and $38.1 \%$ of students had never used such application as their practical learning tool.
\end{abstract}

Keywords-Android Studio; Process Control; MyAras; Virtual lab; Mobile application

\section{Introduction}

The needs of process control in industry is rather significant to ensure safety, smooth process run, less disruption, and as to facilitate in maintenance work. Level, temperature, pressure, velocity and $\mathrm{pH}$ are among the variables that are crucial to be monitored in industry. Those variables are controlled commonly using the Proportional-Integral-Derivative (PID) control scheme, which is the most common practice that consist of about $90 \%$ applications in industry $[1,2]$. 


\begin{tabular}{|l|l|}
\hline \multicolumn{2}{|c|}{ Nomenclatures } \\
\hline OBE & Outcome Based Education \\
\hline JKKP & Department of Chemical and Process Engineering \\
\hline ADDIE & Analysis, Design, Development, Implementation and Evaluation \\
\hline
\end{tabular}

Therefore, the control scheme is underlined in the syllabus of Chemical Engineering Program at Faculty of Engineering and Built Environment (FKAB), Universiti Kebangsaan Malaysia aiming to produce the best future engineers. They were introduced with process control in KKKR3684 (Dynamic and Process Control) course [3]. At the end of this course, student should be able to develop a chemical and biochemical processess model as per requirement to control system design, to design feedback controller for chemical and biochemical processes, to use Matlab software to solve design of feedback control, to analyse the characteristic stability of feedback control system. using frequency response technique and ability to tune feedback controller and size control valve and to design of controllers for integrated complex chemical processes. The engineers in the making must also able to handle practical work, thus a laboratory course is embedded with the third year students. They are required to undergo the KKKB3642 (Biochemistry Engineering Laboratory IV) as part of their prerequisite for graduation.

Two of the laboratory task involve learning of process control related experiments namely Experiment A1: Skid Control and Experiment A2: Tuning and Liquid-level Controller [4]. Those labs enable students to apply their control theory in a small scale equipments that are likely being implemented in industry. Strengthening the knowledge of process control by doing experiments is one of the best techniques to practice. However, appropriate experimental methods need to be emphasized so that the objectives of experiment achieved. Laboratory tests conducted in large scale of students did not guarantee that all of them were involved and understood the experiment.

As in JKKP, a laboratory experiment session was conducted in two groups simultaneously but the optimum number of students was only two people thus their learning time per student is limited [5]. Besides that, due to old version of equipments, high and frequent maintenance is required thus affected the schedule. Therefore, as an alternative a mobile-based virtual lab is developed to provide unlimited access to students at any time and to overcome the equipments' malfunction issue. In addition, it is also an approach to align with the 4.0 industrial revolution emphasized by the Ministry of Higher Education of Malaysia.

Virtual learning has emerged due the rapid development of internet, computers and smart mobile phone and have proven to enhance student's achievement, educational access and reduce cost in education. It is a method of delivering instruction to students using computers, internet or applications. One of the example of such learning technique is the virtual lab [4]. The development of mobile virtual labs is growing rapidly as it has the advantages in terms of security, cost and time devoted to conducting experiments. Therefore, it is the best option to be used especially all the current generation of students are attracted to the mobile and computerized technology. Furthermore, by developing a mobile based virtual lab, which application is closer and 
easy to access since most of them have a smart phone give them the opportunity to cultivate all generic skills as well as self-learning based on experience are important in the new approach of teaching in the OBE era [6].

In order to provide a new experience to the students and to reduce the cost and experimental time, a software needs to be developed and expanded. In this work, Android application was chosen as it has many advantages over other mediums. For example this application can be accessed without internet connection. Android Studio software was chosen for this study because it has easy and easy-to-undo.

Through the development of this mobile virtual lab application, the mechanism of tank level control could be understood and practiced virtually and anytime. It could also solve the conventional laboratory problem which is often malfunction and require high maintenance cost and a long time to repair.

\section{Methodology}

Several steps have been implemented in developing the mobile-based virtual lab including system development and technical development methodology, visual interface, system requirements and assessment design. The mobile virtual lab imitates the process control of a liquid-level system as in the Biochemical Engineering Laboratory IV (KKKB3642), which is Lab A2: Tuning and Liquid-level Controller. The learning content proposed in the mobile application emphasized on every step of the process control skill. Figure 1 depicts the schematic diagram and control loop involved in the conventional A2 laboratory that need to be studied throughout the experiment.

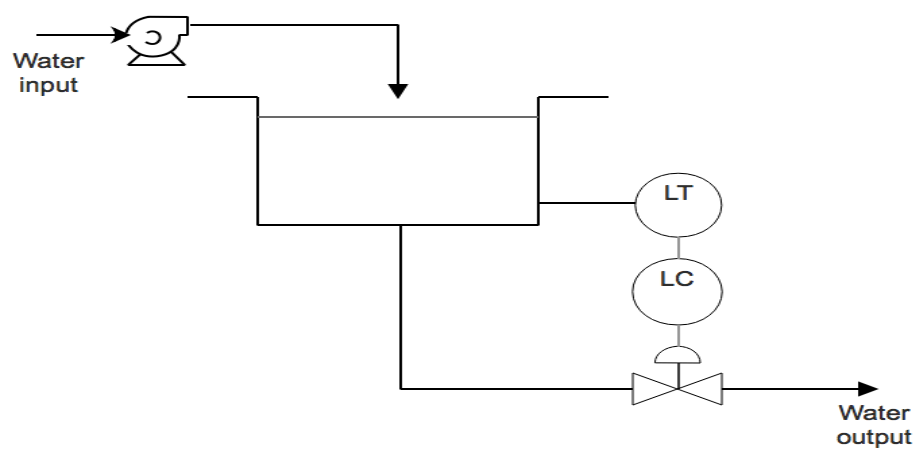

Fig. 1. Process control system to control the level

A structured methodology has been selected to be used in this research, which based on Analysis, Design, Development, Implementation and Evaluation (ADDIE) model to ensure that this developed prototype can be completed in an organized manner. This model outlines systematic steps in developing software and is a formulation that encompasses all components in the previous models. There are five phases of related activities that guide the development of teaching programs or learning modules which are discussed in the following subsections. 
The research methods implemented for MyAras: Level 1 Mobile Virtual Lab is the preparation of database based on the A2 (Tuning and Liquid-level Controller) followed by questionnaire on mobile virtual lab awareness among students and JKKP lecturers. The development of MyAras software is the most important step in this study. The methodology in this article are categorized in three section which are;

\subsection{Preparation of questionnaire on mobile virtual lab awareness}

Virtual reality is a system that allows users to step into a computer-generated virtual environment where humans and computers interact with virtual reality technology. There are various definitions related to virtual reality which all can be considered in accordance with knowledge and skills of previous researchers.

According to virtual reality is a way in which humans can view, manipulate and communicate with computers that involve too complex data. Visualization refers to how a computer produces visuals that may involve CAD (Computer Aided Design) model or scientific simulation. Users can interact and manipulate object directly in virtual reality.

The mobile virtual lab awareness among students and JKKP lecturers should be identified before the implementation of this project. A total of thirteen lecturers and eight four students participated in the questionnaire. The questionnaire on this issue was conducted online using 'google form' and can be seen through the link below: https://goo.gl/forms/hH2mE2rBNRiJ5Qcv1

\subsection{Database setup}

Database is a technique of systematic arrangement of data storage. The preparation of databases for tank-level process control is by performing the tuning and liquidlevel system control scheme. The objective is similar with the conventional laboratory introduced earlier. The virtual laboratory will demonstrate the open loop tuning procedure in the loop of fluid-level process control.

The database will include among others the output data and response rate of the system to be used to compute the values of ratings, integrals and derivatives. From the information, tuning will be carried out using two popular control tuning method namely Ziegler-Nichols and Cohen-Coon methods.

\subsection{Mobile virtual lab software model}

Development of mobile application is often related to smart phones. The application and utilization of device has provided great benefits to technology development. In the virtual lab app technology, for example, smart phones have a huge impact in processing information quickly and effectively. The effectiveness of information generated can improve understanding especially for the public needs.

For the implementation of mobile virtual lab apps, it involves Android smartphones. Android requirements used in this study is Android operating system version 2.2 (Froyo). Figure 2 shows the development flow chart that include input 
flowchart and main menu flow chart. The relationship between the rate of liquid output level the liquid level is shown in flow chart of Figure 3.

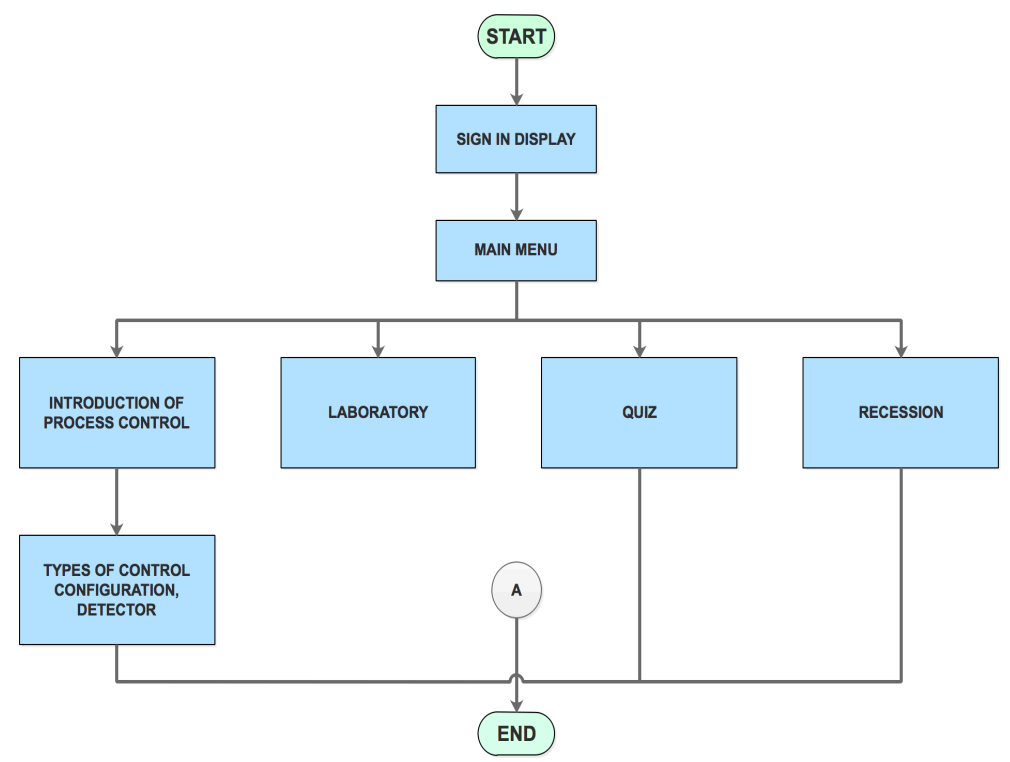

Fig. 2. Input and main menu flow chart

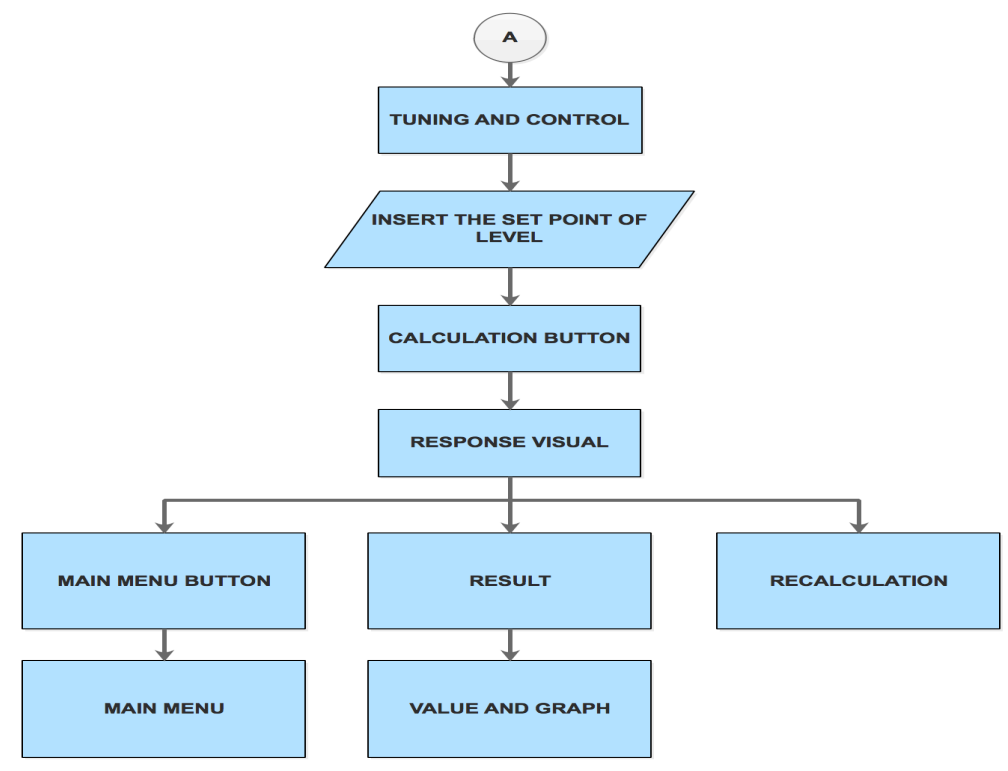

Fig. 3. Flow chart of correlation between rate of liquid output and liquid level 


\section{Results and Discussion}

The cooperation received in getting the feedback from the questionnaire from the participation of 84 students and 13 lecturers of JKKP was impressive. The awareness of mobile virtual lab in a questionnaire was answer by lecturer who is not connected to the project and is not teaching process control. Figure 4 refers to the awareness of mobile virtual labs and Figure 5 is a comparison of mobile virtual and conventional labs preferred by the participants. Around $38.1 \%$ students have no idea about mobile virtual lab while only $8.3 \%$ are aware about the existence of the virtual lab. However, most students choose virtual laboratory $(81 \%)$ due to exposure with the current computing technology trend. In contrast, $76.9 \%$ lecturers prefer conventional laboratories because they want the students to experience real hands-on applications.

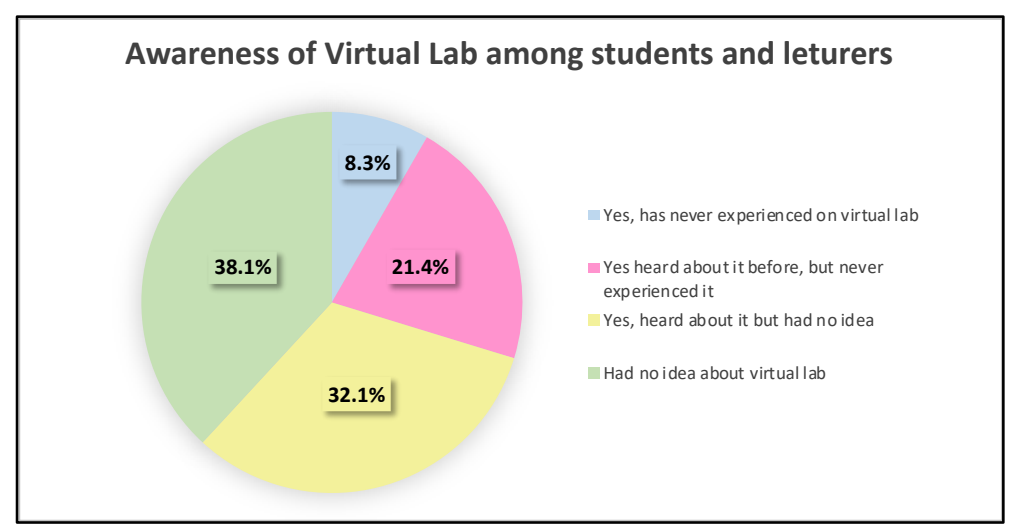

Fig. 4. Awareness of Mobile Virtual Labs among students and lecturers

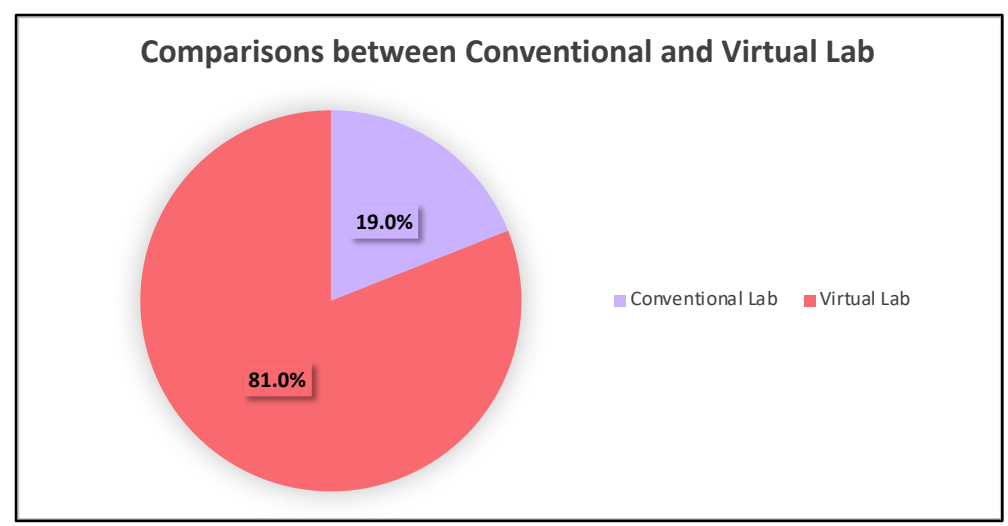

Fig. 5. Comparison Between Mobile Virtual And Conventional Labs Options

The target customer for this mobile-based virtual lab is mainly for the students thus from the survey as in Figure 5, it is has a potential to be developed. The proposed 
virtual lab is called MyAras: Level 1 Mobile Virtual Lab, which means that it is still in the early stage of development and has not been fully launched to all students. In this Level 1, the objectives are to cover the interest of our customers (students) and developing the interface using the Android software. The interface is design in such a way that it will be a user friendly and easy to understand with the appropriate guide words in every interface.

Starting the application, students will see the interface as illustrated in Figure 6. They will then being prompt the instructions on the following steps and begin their experiments. Once the results are obtained it will be stored in the database and can be used for computing the tuning parameters. Students may appreciate the steps of handling the experiments on their own without the need of lab assistant, which in normal practice when they arrived to carry out lab work all the start-up procedure of all equipment have been performed by the lab assistant. This is one advantage of the mobile virtual lab compared to the conventional lab. Furthermore, students are able to access to the lab anywhere, anytime and can repeat the experiments until they obtained a satisfactory results without time frame and cost. This research quite similar with [7,8,9] but different application which is this MyAras for chemical engineering student whereas [7,9] for science programme.

MyAras has been successfully implemented with Android software but improvements still need to be done to improve the overall application before it is launched students in the coming semester. From the information in Figure 6, tuning will be carried out using two popular control tuning method namely Ziegler-Nichols and Cohen-Coon methods $[10,11,12]$. The limitation for this application is calculation of error for each type of tuning was not embedded in the system as proposed by $[13,14]$.

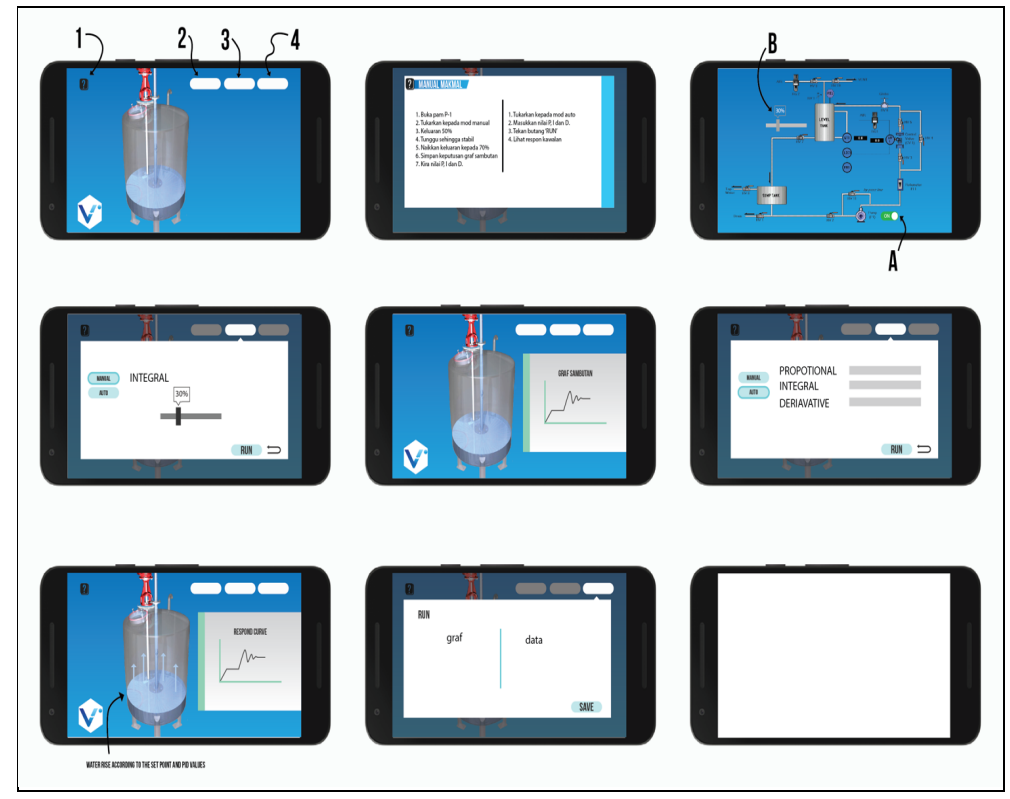

Fig. 6. Home Page Interface 


\section{Conclusion}

Overall, this developed application has helped both parties, student and lecturer in increasing the value of learning and teaching in this era of globalization. MyAras: Level 1 Mobile Virtual Labs means this virtual lab is still in the experimental development stage that starts with the cooperation of students and lecturers on the awareness and importance of mobile virtual lab. Preliminary study found that $81 \%$ of students were interested in running this mobile virtual lab but $38.1 \%$ of students never used this type of application. This software is under early stage i.e development phase and not in beta test stage.

\section{Acknowledgement}

We would like to thank the project leader AP-2014-008 and GGP -2017-084 who has funded this paper.

\section{Refferences}

[1] J. Mendes, L. Osório and R. Araújo, "Self-tuning PID controllers in pursuit of plug and play capacity," Control Engineering Practice, vol. 69, pp. 73-84, 2017. https://doi.org/10. 1016/j.conengprac.2017.09.006

[2] Mohd Zaki Abdul muin. 1998. Kejuruteraan Kawalan. Dewan Bahasa dan Pustaka. 1-26.

[3] T. F. Edgar, D. M. Himmelblau and L. S. Lasdon, Optimization of Chemical Processes, $2^{\text {nd }}$ Edition. New York: McGraw Hill, 2001.

[4] R. Heradio, L. de la Torre and S. Dormido, "Virtual and remote labs in control education: A survey”. Annual Reviews in Control, vol. 42, pp. 1-10, 2016. https://doi.org/10.1016/j. arcontrol.2016.08.001

[5] M. Casini, A. Garulli, A. Giannitrapani and A. Vicino, "Remote pursuer-evader experiments with mobile robots in the automatic control telelab," in $10^{\text {th }}$ IFAC Symposium Advances in Control Education The International Federation of Automatic Control, Sheffield, United Kingdom, 2013, pp. 66-71. https://doi.org/10.3182/20130828-3-uk-2039.00020

[6] C. Webb, "Report of External Assessor for Biochemical Engineering Programme," Department of Chemical and Process Engineering, Universiti Kebangsaan Malaysia, Selangor, Malaysia, 2007. https://doi.org/10.22438/jeb/40/3(si)/sp-16

[7] Norazilawati Abdullah. 2016. Pembinaan dan Penilaian Makmal Maya Untuk Menerapkan Kemahiran Proses Sains dalam Kalangan Murid. Tesis Sarjana Muda, Universiti Sains Malaysia.

[8] Heradio, R., de la Torre, L. \& Dormido, S. 2016. Virtual and remote labs in control education: A survey. Annual Reviews in Control 42: 1-10. https://doi.org/10.1016/jarcontrol.20 16.08 .001

[9] Liu, D.F. 2015. Integration of Virtual Labs into Science E-learning. Journal of Computer Assisted Learning.

[10] Seborg, D. E., Edgar T. F., Mellichamp D. A., 2013. Process Dynamics and Control, Ed. ke 3, USA, John Wiley \& Sons Inc.

[11] Stepanoupoulus, G. 1984. Chemical Process Control: An Introduction to Theory and Practice. Englewood Cliff: Prentice Hall. 
[12] Lawrence Daley. 218. Handbook of Process Control and Instrumentation (Chemical Engineering). Clanrye International.

[13] Richard C Dorf. 2017. Modern Control Systems. Ed. Ke-13, Pearson.

[14] Perry, R.H. dan Green, D.W. 2007. Perry's Chemical Engineers's Handbook. Ed. ke 8. New York: McGraw Hill.

\section{$7 \quad$ Authors}

N. Abd. Rahman is an associate professor of the Faculty of Engineering and Built Enviroment, Universiti Kebangsaan Malaysia at Research Center for Sustainable Process Technologies (CESPRO) \& Center for Engineering Education Research.

J. Mohd Ali is an educator of the Faculty of Engineering and Built Environment, Universiti Kebangsaan Malaysia at Research Center for Sustainable Process Technologies (CESPRO) \& Center for Engineering Education Research.

M. A. Baharom is a student of the Faculty of Engineering and Built Environment, Universiti Kebangsaan Malaysia at Research Center for Sustainable Process Technologies (CESPRO)

Article submitted 2019-09-30. Resubmitted 2019-10-24. Final acceptance 2019-11-06. Final version published as submitted by the authors. 